Article

\title{
Environmental Values (2-MEV) and Appreciation of Nature
}

\author{
Franz X. Bogner (1)
}

Didactics of Biology, Z-MNU (Centre of Math \& Science Education), University of Bayreuth, NW-1, D-95447 Bayreuth, Germany; franz.bogner@uni-bayreuth.de

Received: 7 December 2017; Accepted: 23 January 2018; Published: 30 January 2018

\begin{abstract}
When monitoring the long history of empirical instruments for environmental attitude measurement, the Two Major Environmental Value model (2-MEV) with its two higher order factors: Preservation (PRE) and Utilization (UTL) has repeatedly and independently been confirmed. PRE assesses preferences towards conservation of nature and the environment, whilst UTL measures preferences towards utilization/exploitation of nature. The latter, however, does not yet include the positive aspects of benefitting from the (enjoyable) use of nature. Consequently, besides the established 2-MEV-battery, additional items from an "Appreciation of Nature" (APR) scale were applied to an Irish sample of 289 secondary school students (age: $M=14.3$ years). Responses to the altogether 30-item battery were applied on an oblique rotation by using the Promax procedure: UTL and PRE appeared as orthogonally related factors, APR correlated to PRE with 0.283 . Based on loading scores, the item number for each subscale was further reduced to make the analysis more manageable in educational outreach sites; on those sites, where completing questionnaires may well be quite unpopular, they are very much needed for planning and fine-tuning educational programs. Therefore, extending the 2-MEV scale with an added scale for Appreciation may help: (i) to judge participants' feedback for adjusting/balancing program contents better; and (ii) to promote appreciation as a successful strategy for shifting individuals away from their individual exploitative preferences.
\end{abstract}

Keywords: 2-MEV model; utilization; appreciation; preservation; environmental attitudes and values; gender

\section{Introduction}

An individual's environmental concern is thought to integrate complex components of many different individual kinds. Early social psychological discussions thus started to establish instruments based on theoretical frameworks to monitor these so-called soft variables. Very often, conceptual definitions focused on evaluating tendencies expressed by particular entities and to monitor degrees of favor or disfavor preferences stated [1]. Commonly, attitudinal responses are framed into a tripartite model consisting of cognitive, affective and behavioral components. Consequently, research dealing with related concerns followed that line but still needed simplification by crystallizing the essential roots of potential constructs. With regards to attitudes, many grass root researchers laid (philosophical) foundations going back to Dewey [2,3], Muir [4] or Leopold [5], and later to Carson [6], just to name some major early pioneers. Later in the 1970s, research extracted paradigmatic messages in highlighting these new conservation preferences (e.g., New Environmental Paradigm [7]; New Ecological Paradigm [8]; or Ecological World View [9]). Simultaneously, but in contrast, the term "Dominant Social Paradigm" was coined subsuming anthropocentric views by highlighting exploitation and utilization of our planet as an unlimited resource for human consumption and unlimited growth phantasies [10].

A deeper reason for the need for empirical instruments to measure children's environmental attitudes originates from the demand to provide valid information about the efficacies of educational 
field center activities [11,12]. Early instruments, constructed to measure anthropocentric or eco-centric views [13] culminated in the New Environmental Paradigm (NEP) [14]. Within the NEP scale, environmental attitudes were initially conceived as unidimensional [7], although conflicting studies simultaneously disputed three dimensions. While most of the instruments were developed by psychologists and sociologists for adult populations, in the 1990s, development of the 2-MEV scale (2 Major Environmental Values) for the age-group of adolescents began [15-17]. This battery, based on a solid theoretical foundation, was defined and designed to measure based on primary factors two higher order factors: Preservation (PRE) and Utilization (UTL). A 20-item model was shown to sufficiently measure both constructs, 10 items measuring the PRE-factor incorporating primary factor-analyzed subscales such as "Intent of Support", "Care with resources" or "Enjoyment of nature"; and 10 items measuring UTL with subscales such as "Human Dominance" or "Altering Nature". The term "values" follows a convention established by Rokeach [18] that refers to item-set based first-order factors as "attitudes" and higher-order factors as "values"; hence, in the following, the term "environmental values" is applied. Wiseman and Bogner [19] described the higher order factor PRE as "a bio-centric dimension that reflects conservation and protection of the environment" and UTL as "an anthropocentric dimension that reflects the utilization of natural resources" (p. 787).

The initial development of the 2-MEV instrument in the 1990s was just another attempt to measure green attitudinal variables amongst many earlier ones. Therefore, the authors of the 2-MEV searched for additional support by applying cross-validation studies as an added measure of their validity. (i) A first study included personality variables reflecting risk-taking behavior [20] and strongly supported two orthogonal dimensions: High scorers on Preservation turned out to be controlled and cautious gamblers, while Utilizers failed to control risk-taking behavior. (ii) A second study applied Eysenck and Eysenck's [21] scale to measuring personality variables "Psychoticism" (P), "Extraversion" (E) and "Neuroticism" (N) and included a measure of social desirability (L) [19], again supporting an orthogonal, two-dimensional representation of both ecological values: High scorers in Utilization preferred immediate self-orientated gratification, while an individual preferring Preservation preferred a delayed, otherwise-oriented gratification. (iii) A third study [22] examined the relationship between Preservation and Utilization on the one hand, and Authoritarianism on the other hand, showing a negative correlation of Authoritarianism with PRE and a positive one with UTL. (iv) Bilateral applications within the cultural diversity of Europe (with its many languages) brought additional security to the 2-MEV model and also highlighted differences within the countries involved (e.g., [23-26]. (v) Younger pupils when self-reporting may tend to respond in a more socially desired direction, which often tends to modify the scores when compared to their older peers [27-29]. Thus, Oerke and Bogner [30] first analyzed this possibility by applying a social desirability measure which revealed no moderating effect for instance on the relationship between environmental attitudes. However, the effect size of the Preservation measure is increased nonetheless to some extent. This needs consideration when outcomes of environmental issues are interpreted especially when comparing differently aged cohorts. (vi) Finally, application of the 2-MEV to teacher communities expanded the validity to encompass adult age-groups by again showing an extraordinary construct stability [31]. This extension of age range was also validated even when the scale was applied to many different European countries with different language and cultural backgrounds [32].

A quite new dimension of support for the 2-MEV model finally appeared, when independent research teams also confirmed the two-factor second order structure: (i) Milfont and Duckitt [33] coming from a psychometric background and using a sample of $455 \mathrm{New}$ Zealand subjects confirmed the two-factor second-order structure of the 2-MEV model despite including a large number of items doubling the number of applied primary factors. (ii) Some years later, an US-American group (coming from an instructional background) employed the model for evaluation purposes in outreach "earth education" programs [34,35], again confirming the secondary higher-order structure of PRE and UTL. (iii) Likewise, a Flemish study (coming from a pedagogical background) applied the 2-MEV model within a statewide eco-school initiative, again obtaining the two-factor structure and simultaneously 
highlighting the evaluative potential of the battery [36,37]. (iv) Finally, within the context of evaluating an outreach education program, even a West African sample (coming from a psychological-pedagogical background in developing country) extracted the same two-dimensional structure before applying it to the study design [38]. Thus, to date, the 2-MEV finds itself in the exceptional situation of repeated independent confirmations from a variety of backgrounds, and enjoys worldwide usage now in close to 30 different language versions. Thus, the 2-MEV provides multiple benefits: Besides offering a fixed dimensional structure, it allows between-study comparisons whilst simultaneously matching the current thinking on measuring environmental values [36,37]. Consequently, it is essential to the 2-MEV that it does not imply a conflict between assigning importance to preserving the environment whilst recognizing the need to make use of natural resources.

The 2-MEV's item wording still gave rise to concern about potential bias, as most of them were originally positively directed. Thus, Kibbe et al. [39] revised some 2-MEV items with a negative wording so hypothesizing that rejection of traditional utilization (as negatively phrased Utilization item) will turn its loading towards Preservation and vice versa; rejection of Preservation (as a negatively phrased Preservation item) does the same as with Utilization. Such methodological research may not yet have ended in a modified battery that measures Preservation and Utilization perfectly, which is the ideal, but its measurement still might need further improvement. However, while the orthogonal factor structure was affected by the rephrasing of several items as simple reverse wording effects on the loading structure, the model turned out as very stable: Slight modifications in item wordings never affected the structure. This stability was demonstrated in various studies, for instance, when the original item battery for adolescents was adjusted to an adult version (for teacher samples) [32] or where some European phrases were accordingly adjusted in samples in subtropical environments [40]. Therefore, relinquishment of exploitative Utilization implied Preservation and vice versa relinquishment of Preservation implied exploitative Utilization [39]. Although the semantic meaning of items changed by simple negative rephrasing, the two factors were shown to be theoretically indistinguishable: Abstention from an exploitative use of nature seems to support preserving the environment.

Utilization of nature, however, may provide a somewhat ambiguous attitudinal preference, as an exploitative utilitarian preference and an appreciative usage of nature includes quite different ways of seeing nature. For the study of Bogner and Wiseman [17,41], for example, the attitudinal objects: environment and nature were regarded similarly: The exploitative Utilization of natural resources is part of the environmental attitudinal space as appreciation for nature and appreciation for environmental protection are regarded as two separate attitude sets. Nevertheless, appreciation of nature signals a contrasted vision to the utilitarian domain, which still is a predominant focus for educational interventions. With the intention to sensitize pupils towards more protective environmental behavior and to identify (and avoid) disastrous anthropogenic interferences, educational programs frequently focus on efforts to reduce impact and to encourage strategies avoiding over-exploitive use of our planet (e.g., [42-44]. Although such strategies pointing to exploitation are unveiling the truth behind all the economic for-ever-growth visions, adolescents are frequently disgusted by such approaches. Consequently, such moves increasingly have been shown as not supporting individual behaviors e.g., [2]: Kaiser, Oerke and Bogner [45], for instance, pointed to some negative correlations even when promoting ecological behavior was the only intention of an intervention. Consequently, badmouthing exploitative utilization preferences seems to be followed by the expected ecological behavior when controlling for preservation [46,47]. By contrast, the appreciation of nature may offer a positive correlation to more ecological behavior [48,49]. Appreciation of nature may offer a pathway synonymous with a positive disposition to gratifying experiences of nature in natural settings [50]: People who appreciate nature seem to develop better preferences and to favor environmental protection [51].

The present study focusses on examination of the relationship of Appreciation to the established factors of the 2-MEV higher order factors: Preservation and Utilization. Thus, the study's objectives 
were three-fold: (i) to examine the potential independence of three factors out of a simultaneously applied questionnaire; (ii) to define the factors including its relationships; and (iii) to reduce the item number as much as possible without losing reliabilities and validities (to facilitate its applicability to outreach educational programs).

\section{Methods and Procedures}

In total, 289 secondary school Irish students, 203 males, completed a paper-and-pencil questionnaire during regular school schedules. Ages ranged from 13 to 18 (mean 14.3). The questionnaire consisted of the usual demographic items, of 20 items of the 2-MEV scale $[16,17,26,39]$ and of 15 Appreciation items of Brügger et al. [43] and Kaiser et al. [52]. The 2-MEV's items were taken from Kibbe et al. [39], as the items' wording was repeatedly further simplified due to wide usage all over the world (currently 28 language versions are known). The appreciation measure was taken from the original study of Brügger et al. [43]. However, a factor-analyzed approach was applied instead of the originally favored a Rasch-analyzed testing approach to avoid two different analyses measures and thus facilitate its better applicability at outreach facilities. For the very same reason, the 7 highest loading items on each higher order factor were selected. The response pattern followed a 5-point Likert scale ( $1=\mathrm{I}$ totally disagree, $5=$ I totally agree): A nature-oriented person would, therefore, score high in Preservation and Appreciation, but low in Utilization.

Analyses were conducted using IBM SPSS Statistics 21. An initial factor analysis of all applied items yielded three subscales (APR, UTL, PRE) (the initial PCA scores are not shown here): the 7 highest loading items of each subscale were combined and again subjected to a factor analysis yielding a clear three factor structure. In general, PCA was applied as the structures factor had been repeatedly approved regarding the 2-MEV during the long line of studies (e.g., $[26,38,53])$.

\section{Results}

The 21 items of our reduced item-set were subjected to a Component Analysis (PCA) including a subsequent oblique rotation using the Promax [54] procedure with kappa set to the default value of 4. For readers unfamiliar with Promax, the method first performs an orthogonal rotation of the components, and then raises the resulting loadings to the power kappa, so that the smaller the loading, the greater the reduction in absolute size, yielding an approximation to simple structure with correlated components. The initial signs are restored, producing an "ideal" target matrix. The orthogonal solution is then rotated to maximum conformity with this target using the method of least squares. The Promax solution is displayed in Table 1. Three clear separate factors emerge: Appreciation (APR), Utilization (UTL) and Preservation (PRE).

Of interest in the present paper, of course, are, besides the clear and distinct loading scores, the inter-correlations of the three factors. The approximation to orthogonality of UTL and PRE originally proposed in Wiseman and Bogner [19] is confirmed: $r_{U T L X P R E}=-0.161$ is the equivalent of a mere $2.6 \%$ common variance and an angle of $89.7^{\circ}$ between the two vectors-so close to $90^{\circ}$ that, for all practical purposes, UTL and PRE may be considered orthogonal. APR and UTL are uncorrelated: $r_{A P R x U T L}=0.037$. The correlation between APR and PRE, however, is appreciably higher: $r_{A P R x P R E}=0.283$, reflecting $8.2 \%$ common variance, and an interfactor angle of $81.7^{\circ}$, substantively different from $90^{\circ}$. PRE, of course, remains an important factor in its own right, $91.8 \%$ of its variance being independent of APR. The communality scores range from 0.634 (item: I take time to watch the clouds pass by) to 0.276 (item: I save water by taking a shower instead of a bath (in order to spare water)). The total scale's reliability scored 0.690 , removal of items in almost all cases would decrease this score, just for three items a slight increase to 0.700 would have occurred. Of interest in the present paper is less the loadings than the inter-correlations of the three factors, as shown in Table 2. As expected, PRE is positively correlating with APR, while both relate negatively with UTL. Nevertheless, the scores never exceeded 0.3. This relationship may explain why, for instance, the item "Pets are part of the family" was able to substitute the original enjoyment item "I have 
a sense of well-being in the silence of nature". Repetition of factor analyses without the "pet-item" did not affect the factor structure anyway. Thus, the power of all three the factors is encouraging. The sample's age-group contained secondary school cohorts. Age and gender were not separately analyzed, as earlier studies consistently showed no difference for our sample's age-group [26].

Table 1. Wording of all selected 21 items: seven of each portrayed the factors Preservation (PRE), Utilization (UTL) and Appreciation (APR). Factor loadings were extracted via principal component analysis (Promax, kappa $=4$ ), all loading below 0.3 for reasons of simplicity were suppressed.

\begin{tabular}{|c|c|c|c|}
\hline & \multicolumn{3}{|c|}{ Component } \\
\hline & APR & UTL & PRE \\
\hline I consciously watch or listen to birds & 0.807 & & \\
\hline I take time to watch the clouds pass by & 0.768 & & \\
\hline I deliberately take time to watch stars at night & 0.709 & & \\
\hline I take time to consciously smell flowers & 0.687 & & \\
\hline I enjoy gardening & 0.661 & & \\
\hline I personally take care of plants & 0.594 & & \\
\hline Listening to the sounds of nature makes me relax & 0.572 & & \\
\hline We must build more roads so people can travel to the countryside. & & 0.673 & \\
\hline Nature is always able to restore itself. & & 0.596 & \\
\hline Our planet has unlimited resources. & & 0.591 & \\
\hline We do not need to set aside areas to protect endangered species. & & 0.575 & \\
\hline People worry too much about pollution. & & 0.533 & \\
\hline The quiet nature outdoors makes me anxious. & & 0.505 & \\
\hline We need to clear forests in order to grow crops. & & 0.396 & \\
\hline Humans don't have the right to change nature as they see fit. & & & 0.645 \\
\hline Human beings are not more important than other creatures. & & & 0.556 \\
\hline I save water by taking a shower instead of a bath (in order to spare water). & & & 0.536 \\
\hline Dirty industrial smoke from chimneys makes me angry. & & & 0.532 \\
\hline Humankind will die out if we don't live in tune with nature. & & & 0.514 \\
\hline Not only plants and animals of economic importance need to be protected. & & & 0.497 \\
\hline Pets are part of the family & & & 0.422 \\
\hline
\end{tabular}

Table 2. Inter-factor correlations scores $(1=\mathrm{APR}, 2=\mathrm{UTL}, 3=\mathrm{PRE})$.

\begin{tabular}{cccc}
\hline Component & $\mathbf{1}$ & $\mathbf{2}$ & $\mathbf{3}$ \\
\hline 1 & 1.00 & 0.04 & 0.28 \\
2 & & 1.00 & -0.16 \\
3 & & & 1.00 \\
\hline
\end{tabular}

\section{Discussion}

The repeatedly confirmed 2-MEV structure again appeared when factors behind the applied items were extracted; given the number of repeated confirmation studies, this constancy was not surprising [33-36,38]. This factor-analyzed structure is even true when (as in our case) a mere seven items were used to cover each subscale. Earlier studies when also using reduced item-sets reported the very same pattern: Schneller et al. [40], for instance, successfully applied 12 items (of the original 20) to a Mexican adolescent sample, and still extracted the two higher order factors of PRE and UTL (although some items were adjusted towards subtropical situations).

The reduced 14-item battery of the 2-MEV also proved sufficient validity in supporting the well-known bi-dimensional structure. Exchanging some items or reducing them apparently does not interfere with its validity and reliability. Thus, reducing the mere item numbers seems feasible and it improves the likelihood of its use in outreach studies, where assessment tools as short as possible are required. This request has already found its first solution in the 20-item battery of the 2-MEV scale, which originally started from dramatically higher numbers [15]. Nevertheless, even a further 
reduction of the 2-MEV battery with its original 20 items seems at a first glance redundant but we need to acknowledge that participants are never coming to outreach facilities eager to sit down and complete questionnaires. The shorter a scale is, the more likely is its use in an outreach setting. Evaluators in outreach programs regularly need to monitor (and to justify) the value of participation and to isolate the validity of the reasons for participants' coming to a field center where these are not known beforehand. Increasingly, field centers need to justify and assure the potential outcomes from participation. Here, the robustness of the 2-MEV robustness plays an important role. For instance, a repeated factor-analytic study involving large cohorts of repeated annual application of the 2-MEV in the US has shown a striking constancy over a period of eight years [53]. Furthermore, even within isolated intervention studies the 2-MEV model's consistency over three repeated testing periods has shown a remarkable high level of constancy of precise loading patterns [55].

Although the 2-MEV enjoys frequent application even within different languages a need for extending the construct has repeatedly been expressed, especially with regard to the utilitarian domain. Utilizing nature may consist of two aspects: the 2-MEV defined that domain as exploitative (see items in Figure 1), appreciation of nature may offer another interpretation of utilization [39]. Therefore, appreciation for nature can be easily regarded as a positive attitude towards nature, as the appreciative component in the environmental attitudinal space may promote a substantial expectation favoring or even actively supporting environmental protection. For instance, Mayer and Frantz [48] had emphasized the emotional component of connectedness to nature is a substantial trait predicting attitudes in favor of environmental protection. While an exploitative Utilization, as defined in the 2-MEV-Model, covers preferences to alter nature, dominate, harm or exploit resources, an appreciation of nature as source of relaxation and inspiration may finally lead to a greater pro-environmental behavior (see: [56-58]). Consequently, activities in nature for relaxation and inspiration may lead to bonding which in turn suggests the need to indirectly measure self-reported past behaviors of appreciative usages of nature. Regarding the construction of a battery of questions, any higher appreciation score of a person may express her/his connection and engagement in progressive appreciative behaviors and express appreciation for nature in other ways.

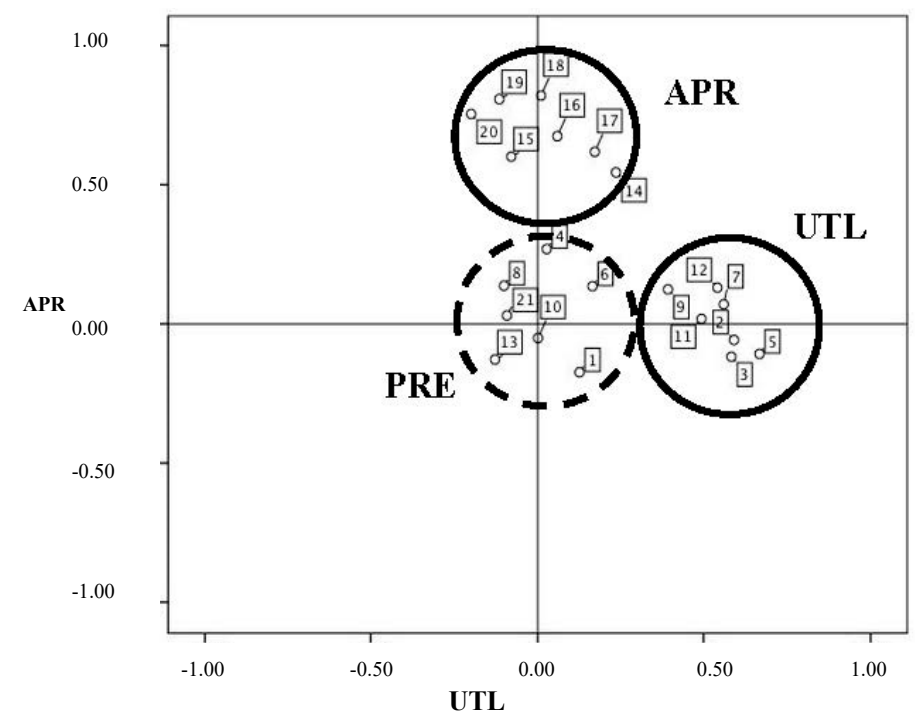

Figure 1. This two-dimensional representation of the three-dimensional structure shows the distinct location of all three factors. The dotted circle represents the PRE-factor, located in the space before/after the dimensions APR and UTL. Note that this orthogonal representation is a convenient but inaccurate reflection of the oblique solution discussed.

From a technical point of view, the three factors APR, UTL and PRE altogether explain $40 \%$ of the variance, leaving $60 \%$ unexplained. This is reflected in the number of low communalities. Recall 
that commonalities measure the proportion of variance of each variable that can be explained by the factors. Thus, $16.5 \%$ of the variance of the item "Pets are part of the family" is explained by the three-factor solution: that is, restricting the solution to the three largest components leaves some $80 \%$ of this variable to be explained by factors not extracted. Consequently, this item seems quite different from other aspects of appreciation of nature which may originate in many reasons: Families with a strong appreciation of nature may not have pets, for instance, due to reasons of cost, allergies, lack of time to care for them, or whatever. Consequently, as this item is regarded as a problematic one, it was removed. The highest communality, associated with the item "I consciously watch or listen to birds", is 0.634 , or $63.4 \%$ of variance explained by the three-factor solution. This in no way detracts from the quality of the three-factor solution, but it does suggest that a good deal of further information is contained in the 20-item questionnaire. This is a possible area for future research.

Without any doubt from a pedagogical perspective, the positive message of appreciation is expected to provide a valuable trigger for convincingly showing change of individual behaviors (see introduction) [29,59]. The adolescents' age group expects positive approaches to be more meaningful, not because this cohort is not responsible at all for any environmental implementation, but because this age-group has a more optimistic view of the world. Not only commercial advertising follows this principle but also EE/ESD research strongly supports this view as well, negative advertising may lead to less effective outcomes as the personal vulnerability of adolescents to bad outcomes seem not to exist [60]. For the age group of children and adolescents (the most likely cohort of educational efforts), positive approaches are more meaningful, as a major characteristic of this age-group is a tendency to adopt more optimistic points of view that nothing bad will happen. Negative advertising may turn out to be less effective with audiences that do not feel personal vulnerability for bad outcomes [60]. Additionally, the young generation cannot be made to feel responsible for already existing nature exploitation [61]. Therefore, a positive approach to help and care for nature will turn out as the better way to transmit such messages: When attempting to sensitize young people, we often pick out clashes, apparent disasters or point to newly unleased scandals with the conviction that negative examples may promote more holistic conservation initiatives and help to divert them to more appropriate environmental behavior. As adults, we expect that warning examples of "lost battles" may convince adolescents to move faster towards a more ecological-oriented behavior [62]. To cut a long story short, this is an ineffective intention and will not work at all: In education the newspaper vision that bad news generates good news does not work. Positive approaches to help and care for nature will much better prepare the way to spread good messages and eventually lead to (more) positive perceptions and to the adoption of pro-environmental behavior. Firstly, a mere demonizing of exploitative behavior does not prevent exploitation as adolescents are not yet in the position to make big decisions. Secondly, environmental threats are not caused by adolescents and thus confronting them with disasters for which they are not personally responsible may turn contra-productive. However, supporting appreciation for nature through gratifying experiences in natural environments seems to be the most promising direction. Positive approaches including the inclusion of nature appreciation might more strongly affect adolescents' pro-environmental behavior $[57,58,63]$. Moreover, a representative Finnish sample clearly showed besides others that prosocial experience as an enhancing variable better supports individual ecological behavior [64]. Education needs to aim at achieving a sustainable, positive enhancement of attitudes in a pro-environmental direction. Speaking of pro-environmental attitudes, we mean attitudes which may lead to actions that either prevent or reduce harm to the environment or that may even benefit the environment. Educators may intuitively have already known this relationship when they consistently integrated affective nature experiences into their programs. The present study may substantially help educators in their educational efforts.

Acknowledgments: The author is very grateful to the teachers and students contributing to the study as well as to T. Blaine and M. Farren for assisting the data collection. Similarly, S. Tomkins and M. Wiseman have constructively discussed earlier versions of the manuscript. M. Wiseman also supported the statistical analyses. This publication was funded by the German Research Foundation (DFG) and the University of Bayreuth within the funding program Open Access Publishing. 
Conflicts of Interest: The author declares no conflict of interest.

\section{References}

1. Eagly, A.H.; Chaiken, S. The Psychology of Attitudes; Harcourt: Fort Worth, TX, USA, 1993.

2. Dewey, J. Experience and Nature; Open Court: La Salle, IL, USA, 1925.

3. Dewey, J. The Quest for Certainty: A Study of the Relation of Knowledge and Action; Minton, Balch and Company: New York, NY, USA, 1929.

4. Muir, J. A Thousand-Mile Walk to the Gulf; Houghton Mifflin: Boston, MA, USA; New York, NY, USA, 1916.

5. Leopold, A. Sand County Almanac; Oxford University Press: New York, NY, USA; Oxford, UK, 1949.

6. Carson, R. Silent Springs; Houghton Mifflin Harcourt: Boston, MA, USA, 1962.

7. Dunlap, R.E.; Van Liere, K.D. The New Environmental Paradigm. J. Environ. Educ. 1978, 9, 10-19. [CrossRef]

8. Dunlap, R.E.; Van Liere, K.D.; Mertig, A.G.; Jones, R.E. Measuring Endorsement of the New Ecological Paradigm: A Revised NEP Scale. J. Soc. Issues 2000, 56, 425-442. [CrossRef]

9. Blaikie, W.H. The nature and origins of ecological world views: An Australian study. Soc. Sci. Q. 1992, 73, 144-165.

10. Pirages, D.C.; Ehrlich, P.R. Ark II: Social Response to Environmental Imperatives; Freeman: San Francisco, CA, USA, 1974.

11. Hines, J.M.; Hungerford, H.R.; Tomera, A.N. Analysis and synthesis of research on responsible environmental behavior: A Meta-analysis. J. Environ. Educ. 1987, 18, 1-8. [CrossRef]

12. Leeming, F.C.; Dwyer, W.O.; Porter, B.E.; Cobern, M.K. Outcome research in environmental education. J. Environ. Educ. 1993, 24, 8-21. [CrossRef]

13. Arcury, T.A.; Johnson, T.P.; Scollay, S.J. Ecological Worldview and Environmental Knowledge: The New Environmental Paradigm. J. Environ. Educ. 1986, 17, 35-40. [CrossRef]

14. Catton, W.R.; Dunlap, R.E. Environmental sociology: A new paradigm. Am. Sociol. 1978, 13, 41-49.

15. Bogner, F.X.; Wilhelm, M.G. Environmental perspectives of pupils: The development of an attitude and behaviour scale. Environmentalist 1996, 16, 95-110. [CrossRef]

16. Bogner, F.X.; Wiseman, M. Towards Measuring Adolescent Environmental Perception. Eur. Psychol. 1999, 4, 139-151. [CrossRef]

17. Bogner, F.X.; Wiseman, M. Adolescents' attitudes towards nature and environment: Quantifying the 2-MEV model. Environmentalist 2006, 26, 247-254. [CrossRef]

18. Rokeach, M. Beliefs, Attitudes, and Values; Jossey-Bass: San Francisco, CA, USA, 1968.

19. Wiseman, M.; Bogner, F.X. A higher-order model of ecological values and its relationship to personality. Personal. Individ. Differ. 2003, 34, 783-794. [CrossRef]

20. Bogner, F.X.; Brengelmann, J.C.; Wiseman, M. Risk-taking and environmental perception. Environmentalist 2000, 20, 49-62. [CrossRef]

21. Eysenck, H.J.; Eysenck, S.B. Personality Structure and Measurement; Routledge and Kegan Paul: London, UK, 1969.

22. Wiseman, M.; Wilson, G.; Bogner, F.X. Environmental Values and Authoritarianism. Psychol. Res. 2012, 2, 25-31.

23. Bogner, F.X. Environmental Perception of Irish and Bavarian Adolescents. A Comparative Empirical Study. Environmentalist 1998, 18, 27-38. [CrossRef]

24. Bogner, F.X.; Wiseman, M. Environmental perspectives of Danish and Bavarian pupils: Towards a methodological framework. Scand. J. Educ. Res. 1997, 41, 53-71. [CrossRef]

25. Bogner, F.X.; Wiseman, M. Environmental perception of Swiss and Bavarian pupils: An empirical evaluation. Swiss J. Sociol. 1998, 24, 547-566.

26. Bogner, F.X.; Wiseman, M. Environmental perception of French and some Western European secondary school students. Eur. J. Psychol. Educ. 2002, 17, 3-18. [CrossRef]

27. Bogner, F.X. The influence of a residential outdoor education programme to pupil's environmental perception. J. Psychol. Educ. 2002, 17, 19-34. [CrossRef]

28. Liefländer, A.K.; Bogner, F.X. The effects of children's age and sex on acquiring pro-environmental attitudes through environmental education. J. Environ. Educ. 2014, 45, 105-117. [CrossRef] 
29. Thorn, C.; Bogner, F.X. How environmental values predict acquisition of different cognitive knowledge types concerning environmental conservation. 2018, submitted.

30. Oerke, B.; Bogner, F.X. Social Desirability, Environmental Attitudes, and General Ecological Behaviour in Children. Int. J. Sci. Educ. 2013, 35, 713-730. [CrossRef]

31. Oerke, B.; Bogner, F.X. Gender, age and subject matter: Impact on teachers' ecological values. Environmentalist 2010, 30, 111-122. [CrossRef]

32. Munoz, F.; Bogner, F.X.; Clement, P.; Carvalho, G.S. Teachers' conceptions of nature and environment in 16 countries. J. Environ. Psychol. 2009, 29, 407-413. [CrossRef]

33. Milfont, T.L.; Duckitt, J. The structure of environmental attitudes: A first- and second-order confirmatory factor analysis. J. Environ. Psychol. 2004, 24, 289-303. [CrossRef]

34. Johnson, B.; Manoli, C. Using Bogner and Wiseman's Model of Ecological Values to measure the impact of an earth education programme on children's environmental perceptions. Environ. Educ. Res. 2008, 14, 115-127. [CrossRef]

35. Johnson, B.; Manoli, C. The 2-MEV scale in the United States: A measure of children's environmental attitudes based on the theory of ecological attitude. J. Environ. Educ. 2011, 42, 84-97. [CrossRef]

36. Boeve-de Pauw, J. Valuing the Invaluable: Effects of Individual, School and Cultural Factors on the Environmental Values of Children; Maklu Publisher: Antwerp, Belgium, 2011.

37. Boeve-de Pauw, J.; van Petegem, P. The effect of Flemish eco-schools on student environmental knowledge, attitudes, and affect. Int. J. Sci. Educ. 2011, 33, 1513-1538. [CrossRef]

38. Borchers, C.; Boesch, C.; Riedel, J.; Guilahoux, H.; Quattara, D.; Randler, C. Environmental education in Cote d'Ivoire/West Africa: Extra-curricular primary school teaching shows positive impact on environmental knowledge and attitudes. Int. J. Sci. Educ. 2013, 4, 240-259. [CrossRef]

39. Kibbe, A.; Bogner, F.X.; Kaiser, F.G. Exploitative vs. appreciative use of nature-Two interpretations of utilization and their relevance for environmental education. Stud. Educ. Eval. 2014, 41, 106-112. [CrossRef]

40. Schneller, A.J.; Johnson, B.; Bogner, F.X. Measuring children's environmental attitudes and values in northwest Mexico: Validating a modified version of measures to test the Model of Ecological Values (2-MEV). Environ. Educ. Res. 2013, 21, 61-75. [CrossRef]

41. Bogner, F.X.; Wiseman, M. Environmental Perception: Factor Profiles of Extreme Groups. Eur. Psychol. 2002, 7, 225-237. [CrossRef]

42. Bogner, F.X. The Influence of Short-Term Outdoor Ecology Education on Long-Term Variables of Environmental Perception. J. Environ. Educ. 1998, 29, 17-29. [CrossRef]

43. Bogner, F.X. Empirical evaluation of an educational conservation programme introduced in Swiss secondary schools. Int. J. Sci. Educ. 1999, 21, 1169-1185. [CrossRef]

44. Bogner, F.X.; Wiseman, M. Outdoor Ecology Education and Pupils' Environmental Perception in Preservation and Utilization. Sci. Educ. Int. 2004, 15, 27-48.

45. Kaiser, F.; Oerke, B.; Bogner, F.X. Behavior-based environmental attitude: Development of an instrument for adolescents. J. Environ. Psychol. 2007, 27, 242-251. [CrossRef]

46. Kaiser, F.G. A moral extension of the theory of planned behavior: Norms and anticipated feelings of regret in conservationism. Personal. Individ. Differ. 2006, 41, 71-81. [CrossRef]

47. Kaiser, F.G.; Hübner, G.; Bogner, F.X. Contrasting the Theory of Planned Behavior with the Value-Belief-Norm Model in Explaining Conservation Behavior. J. Appl. Soc. Psychol. 2005, 35, 2150-2170. [CrossRef]

48. Kaiser, F.G.; Byrka, K.; Hartig, T. Reviving Campbell's paradigm for attitude research. Personal. Soc. Psychol. Rev. 2010, 14, 351-367. [CrossRef] [PubMed]

49. Brügger, A.; Kaiser, F.G.; Roczen, N. One for all? Connectedness to nature, inclusion of nature, environmental identity, and implicit association with nature. Eur. Psychol. 2011, 16, 324-333. [CrossRef]

50. Kossack, A.; Bogner, F.X. How does a one-day environmental education programme support individual connectedness with nature? J. Biol. Educ. 2012, 46, 180-187. [CrossRef]

51. Nord, M.; Luloff, A.E.; Bridger, J.C. The association of forest recreation with environmentalism. Environ. Behav. 1998, 30, 235-246. [CrossRef]

52. Kaiser, F.G.; Brügger, A.; Hartig, T.; Bogner, F.X.; Gutscher, H. Appreciation of nature and appreciation of environmental protection: How stable are these attitudes and which comes first? Eur. Rev. Appl. Psychol. 2014, 64, 269-277. [CrossRef] 
53. Bogner, F.X.; Johnson, B.; Buxner, S.; Felix, L. The 2-MEV-model: Constancy of adolescent environmental values in an 8-year time-frame. Int. J. Sci. Educ. 2015, 37, 1938-1952. [CrossRef]

54. Hendrickson, A.E.; White, P.O. "Promax: A quick method for rotation to oblique simple structure". Br. J. Stat. Psychol. 1964, 17, 65-70. [CrossRef]

55. Dieser, O.; Bogner, F.X. How individual environmental values influence knowledge acquisition of adolescents within a week-long outreach biodiversity module. J. Glob. Res. Educ. Soc. Sci. 2017, 9, 213-224.

56. Kaiser, F.G.; Roczen, N.; Bogner, F.X. Competence Formation in Environmental Education: Advancing Ecology-Specific Rather Than General Abilities. Umwelt Psychol. 2008, 12, 56-57.

57. Roczen, N.; Kaiser, F.G.; Bogner, F.X.; Wilson, M. A Competence Model for Environmental Education. Environ. Behav. 2014, 46, 972-992. [CrossRef]

58. Roczen, N.; Kaiser, F.G.; Bogner, F.X. Umweltkompetenz-Modellierung, Entwicklung und Förderung [Environmental Competence-Modeling, development and promotion]. Zeitschrift für Pädagogik 2010, 56, 126-134.

59. Bissinger, K.; Bogner, F.X. Environmental literacy in practice: Education on tropical rainforests and climate change. Environ. Dev. Sustain. 2017. [CrossRef]

60. NRC. Adolescent Risk and Vulnerability: Concepts and Measurement; National Research Council (US) and Institute of Medicine (US) Board on Children, Youth, and Families; National Academies Press: Washington, DC, USA, 2001.

61. Branded, Q.A. The Buying and Selling of Teenagers; Perseus: Cambridge, MA, USA, 2003.

62. Schumm, M.; Bogner, F.X. How Environmental Attitudes interact with Cognitive Learning in a Science Lesson Module. Educ. Res. Int. 2016, 2016, 6136527. [CrossRef]

63. Mayer, S.F.; Frantz, C.M. The connectedness to nature scale: A measure of individuals' feeling in community with nature. J. Environ. Psychol. 2004, 24, 503-515. [CrossRef]

64. Uitto, A.; Boeve-de Pauw, J.; Saloranta, S. Participatory school experience as facilitators for adolescents' ecological behavior. J. Environ. Psychol. 2015, 43, 55-65.

(C) 2018 by the author. Licensee MDPI, Basel, Switzerland. This article is an open access article distributed under the terms and conditions of the Creative Commons Attribution (CC BY) license (http:/ / creativecommons.org/licenses/by/4.0/). 